\title{
The Development of A Reliability Evaluation Application for Power Plant Steam Turbine Vibrations to Predict Its Failure
}

\author{
Moch. Faqih, Nu Rhahida Arini, Hendrik Elvian Gayuh Prasetya \\ Power Plant Engineering Study Program \\ Electronic Engineering Polytechnic Institute of Surabaya, Surabaya \\ Email: faqihm45@gmail.com, hendrik@pens.ac.id \\ Correspondence Author: arini@pens.ac.id
}

Received September 11, 2021; Revised October 13, 2021; Accepted November 14, 2021

\begin{abstract}
A steam turbine is the most critical component in a thermal power plant. Due to its crucial function, it should be maintained to be able to operate without failure. This paper aims to develop an application that can be used to analyze the reliability and synchronization of vibrations in a single evaluation through the application. The application is helpful to decide the proper time the maintenance should be performed in order to provide a better maintenance strategy. In this paper, the application was used to make an ease in evaluating the reliability and vibration of a $670 \mathrm{MW}$ power plant steam turbine. The reliability was analyzed by qualitative and quantitative methods. The vibration evaluation using Fast Fourier Transform (FFT) was done by diagnosing the failure symptoms from vibration spectrum. The analysis of synchronization of vibrations conducted by comparing the vibration frequency and the natural frequency of the system which can be calculated easily using the application. The algorithm program of both evaluations was built using GNU Octave software to make a friendly user interface. From the evaluation result, the most critical components of the steam turbine are coupling, labyrinth seals, bearing, diaphragm, turbine control valve, and turbine stop valve. The maintenance interval based on the expected reliability of $90 \%$ produces the highest reliability improvement. Based on the vibration analysis, there is no failure symptoms detected in the turbine bearings. Furthermore, the dominant frequencies of vibration are distant from the natural frequency. Therefore, the steam turbine condition is acceptable to operate.
\end{abstract}

Keywords: Steam turbine, reliability, vibration, GNU Octave.

\section{INTRODUCTION}

Reliability is probability of a component or system operating without any failures for a certain period. The probability is calculated statistically depend on continuous distribution such as exponential, normal, lognormal, and Weibull distribution. In this study, the reliability estimation is based on historical data failure of steam turbine components in the last 20 years of 
operation. By predicting the expected reliability of the components, the time maintenance can be determined appropriately. However, the real-time condition of the steam turbine needs to be evaluated to indicate the necessity of maintenance since failures can happen at any time. Several techniques of monitoring are commonly used to diagnose the behavior of the components such as vibration analysis, oil and wear debris analysis, ultrasonics, thermography, and performance evaluation [1]. The proper technique to assess the condition of the steam turbine is vibration analysis as it is classified as rotating equipment. Vibration monitoring is conducted because it is very effective in predicting the damage of rotating objects [2].

This study aims to propose an application that combines the reliability and vibration analysis in a single evaluation through the application. For the reliability analysis, there are several features provided to calculate and plot the reliability over the time of the component. It also can be used to fit the data distribution as well as calculate the distribution parameters. For the purpose of vibration analysis, the application provides several features to plot the frequency spectrum and calculate the natural frequency of the steam turbine system. This will make failure analysis of the vibration and reliability evaluation more doable and easier.

\section{RELATED WORKS}

Reliability and vibration of steam turbines had commonly been discussed separately by previous researchers. Reliability evaluation is carried out using qualitative and quantitative analysis. Failure Mode and Effect Analysis (FMEA) is frequently used to describe the potential failures and the critical components of steam turbine using qualitative assessment [3][4][5]. A study once examined the diaphragm was the top priority of steam turbine components that should be maintained refered to the highest risk priority number (RPN) [4]. The RPN represents the effect of risk (severity/S), the likelihood of risk (occurrence/0), and the risk opportunities (detection/D). The criteria S, O, D is most commonly scaled by range 1-10 [6]. As a qualitative assessment output, RPN value has a subjectivity influence. The study [6] tried to propose the consistency of RPN that is obtained from FMEA team. A non-parametric correlation test, namely Pearson correlation test, was applied to recognize the RPN consistency is produced using a commercial statistic software, SPSS. Reliability estimation of steam turbine had been conducted quantitatively by previous researches [7][5]. Their estimation is based on historical data failure of the last five years and ten years of operation respectively. The data distribution was fitted using a commercial data analysis softwares such as Reliasoft Weibull ${ }^{++}$and Minitab. Subsequently, the parameter of distribution is obtained to calculate the reliability function over certain time periods. Both researches investigated the effect of maintenance into the reliability of steam turbine system. They found that planned maintenance tasks can reduce the number of unplanned 
trips of the steam turbine. Furthermore, the study [5] proposed the right time to perform maintenance of steam turbine is by applying intervals of 150 days.

The works related to steam turbine vibration had been widely discussed due to the existence of predictive maintenance. Therefore, some researches provide the technique to analyze vibration of steam turbine based on vibration spectrum [8][9][10]. All studies recommended a frequency analysis to indicate the failure symptomps. The most applied and accapted technique is Fourier Transform that is used to convert the time domain data into frequency domain. In order to make an ease, the analysis is done usually by Fast Fourier Transform (FFT) algorithm [8]. The FFT can be processed easily using computational software such as Matlab. The study [9] found that one of the causes of steam turbine vibration is the vapor stream excitation occurs at high-pressure rotor steam inlet end. Another study reported the instability of steam turbine occurred because of unequally distributed steam forces in circumference direction [10]. The vibration can be classified by lateral and torsional vibration. A study explained the lateral vibration can be readily monitored by either direct or indirect measurement. However, the torsional vibration is not easily detected [11]. In this study, the measurement of vibration was acquired from 3300 XL 8mm Proximity Sensor available at power plant. The collected data was lateral vibrations in X-axis (sway) and Yaxis (heave).

The uniqueness of this study resides in the exploration of the another perspective of predictive maintenance strategy to a $670 \mathrm{MW}$ power plant steam turbine. A time-based preventive action was planned using reliability evaluation and combined with condition-based monitoring analysis to support the maintenance schedules. The methods used in this study were adapted from previous researches. However, this work was done using an open-source software, GNU Octave, that is powerful in computation and signal processing.

\section{ORIGINALITY}

According to previous researches, the reliability and vibration of steam turbines become the important factors to be considered to develop a good predictive maintenance strategy. However, sometimes the investigation of reliability and vibration is not straightforward and becomes tedious due to the complexity of its calculation steps. Therefore, this research aimed to propose an interactive user interface that can be used to do the entire calculation process to become easier and faster. The algorithm was developed using a high programming language provided by GNU Octave which has a similarity with MATLAB. In the future, the proposed program can be embedded in power plant control room. The interface created is shown in Figure 1.

A steam turbine which has $670 \mathrm{MW}$ capacity is analyzed in this study. It was installed in one of the primary power plants in Indonesia that provide electricity around Java and Bali island. The steam turbine is a tandem- 
compound type with the configuration of high pressure section, dual-flow intermediate pressure section, and two dual-flow low pressure sections. The historical data failure collected from maintenance database of the last 20 years of operation. Subsequently, it was sorted based on the critical components. The components analyzed are limited to the coupling, labyrinth seals, diaphragm, blade, bearing, shaft, casing, turbine control valve and turbine stop valve. The time domain vibration data collected from vibration monitoring system with 3300 XL 8mm Proximity Sensor. The measurement was acquired on shaft displacement of $\mathrm{X}$ and $\mathrm{Y}$ directions.

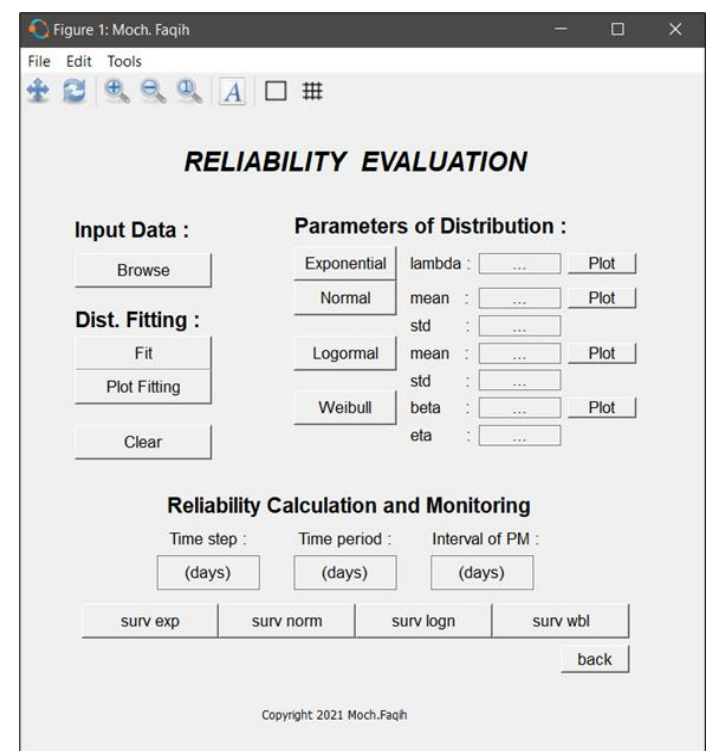

(a)

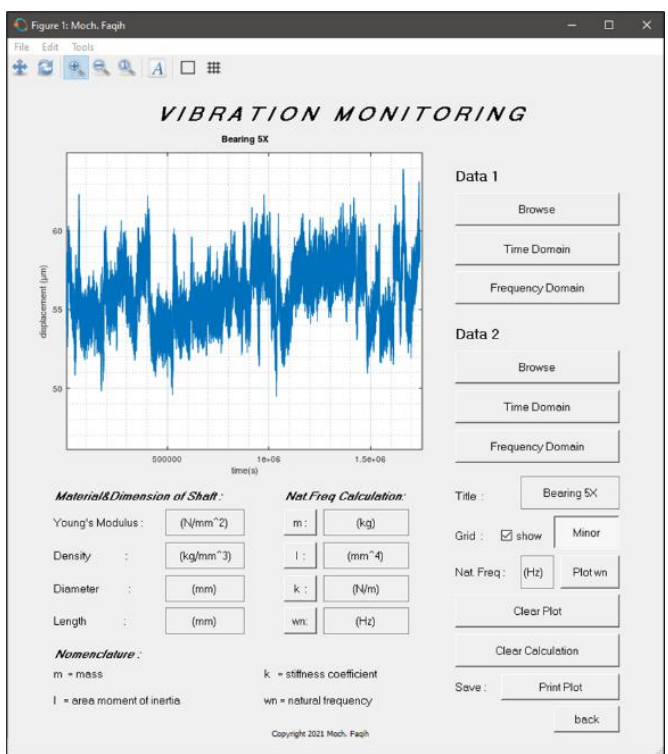

(b)

Figure 1. The interface of (a) reliability analysis (b) vibration analysis.

\section{SYSTEM DESIGN}

The system design is discussed separately into two parts, which are the discussion of reliability evaluation and vibration monitoring. Reliability evaluation contains the procedure to investigate the reliability of steam turbine components. Vibration monitoring describes the steps to convert time domain vibration data to the frequency domain using FFT and fault diagnosis.

\subsection{RELIABILITY EVALUATION}

The failures of steam turbine caused any problems which effect to decreasing performance and lifetime reduction. A qualitative assessment using Failure Mode and Effect Analysis (FMEA) was trusted to describe all potential failures including its causes and effects. The assessment identify the critical components of system represented by Risk Priority Number (RPN). RPN was calculated by multiplying the value of Severity (S), Occurrence (O), and Detection (D). In this study, the potential failures were adapted from previous researches [3][4] and combined with direct identification. FMEA questionnaires was spreaded to 5 respondents in the power plant. The 
respondents were qualified according to their experiences at least 5 years in maintenance division. The respondents were also competent in dealing with various problems of the steam turbine. Therefore, they are expert and capable to fill the $S, 0$, and $D$ ratings. The rating parameters is shown in Table 1,2 , and 3 . The result of the questionnaires should be tested to ensure all the statements were usable to be measurement instruments. The test was done using correlation test of Pearson to identify the accuracy of measurement and inter-rater reliability test of Cronbach's Alpha to measure the consistency. The correlation test conducted with significance level of 5\% (2-tailed). Each statement is denoted to be valid if the calculated coefficient is greater than the critical value of the correlation coefficient [12]. The value of RPN was used to determine the most critical components using Pareto Diagram.

Subsequently, the historical data failure of each critical components was sorted to get time to failure distribution. The failure distribution was modelled as continuous probability distribution such as exponential, normal, lognormal and Weibull. A regression approach of least-squares method was used to fit the distribution. The most fitted distribution was represented by the highest index of fit, $r$ [13]. However, parameters of the distributions estimated using Maximum Likelihood Estimation (MLE) method. Another distribution fitting technique, goodness of fit (GOF) test, was also applied to verify the distribution. This kind of test expressed by hypothesis testing of $\mathrm{H}_{0}$ and $\mathrm{H}_{1} \mathrm{H}_{0}$ declared that the data set might followed the specified distribution and $\mathrm{H}_{1}$ declared the opposite. In this study, specific GOF tests were used to give more powerful decisions. Bartlett's test applied to exponential distribution, Kolmogorov-Smirnov (K-S) test applied to normal and lognormal distribution, and Mann's test applied to Weibull distribution. All of the tests were done at a $5 \%$ level of significance.

As the reliability is defined as probability of component to survive over certain time, then the value ranged from 0 to 1 . It also can be converted to percentage value. The general mathematic expression of reliability followed this Equation (1)

$$
\mathrm{R}(t)=1-\mathrm{F}(t)
$$

$\mathrm{R}(t)$ and $\mathrm{F}(t)$ are reliability function and cumulative density function at time $(t)$. Time, $t$, is a given value that indicates the expected operating time of component.

In reliability engineering, another important issue is the failure rate of components. Every component or system has unique failure rate depends on the length of operational time. It commonly characterized as Decreasing Failure Rate (DFR), Constant Failure Rate (CFR) and Increasing Failure Rate (IFR). A preventive maintenance action normally increases the reliability as though it returns to initial condition. However, it does not work when component having a constant failure rate [12]. Therefore, the failure rate needs to be identified in order to prepare the maintenance program. The failure rate function shown in Equation (2) 


$$
\lambda(t)=f(t) / R(t)
$$

$f(t)$ is probability density function. It described the shape of the failure distribution. In Octave, PDF is easily obtained using provided function in statistic package, as well as CDF.

In predicting the right time to maintain the components, the improvement of reliability should be considered. Reliability under preventive maintenance in general can be expressed by Equation (3)

$$
\mathrm{R}_{\mathrm{m}}(t)=\mathrm{R}(T)^{\mathrm{n}} \mathrm{R}(t-\mathrm{n} T) ; \mathrm{nT} \leq \mathrm{t} \leq(\mathrm{n}+1) \mathrm{T} ; \mathrm{n}=0,1,2 \ldots
$$

$\mathrm{R}(T)^{\mathrm{n}}$ and $\mathrm{R}(t-\mathrm{n} T)$ are the reliability at $n$ maintenance interval and the reliability of the previous maintenance at $t$-n $T$. In this study, the maintenance interval, T, varied by Mean Time To Failure (MTTF) and the time when the component reaches reliability of $80 \%$ and $90 \%$. The MTTF can be calculated using Equation (4)

$$
\mathrm{MTTF}=\int_{0}^{\infty} \mathrm{R}(\mathrm{t}) \mathrm{dt}
$$

After evaluating the reliability without maintenance and under the desired maintenance interval, the values were plotted together to compare each other.

\subsection{VIBRATION MONITORING}

Vibration is oscillating motions of component that make it moves from its initial position. The primary properties involved to the phenomenon of vibrations are mass, stiffness, and damping. In the case of steam turbine, mass, stiffness, and damping referred to turbine rotors, shaft and bearings. The properties played a major role in reacting to any forces caused the vibrations. Therefore, some theoretical mathematical models has been developed to predict the vibration and its behaviour. However, vibrations also can be measured by direct measurement. Proximity probes was the preferred vibration tranducers to monitor the vibration of rotating equipments [1]. In this case, the steam turbine used 3500 Monitoring system with two proximity probes mounted to the bearings. The sensor allowed to collect time domain displacement data in $\mathrm{X}$ and $\mathrm{Y}$ directions. The time domain data only presents the overall displacement amplitude in series of time. In signal processing area, the time-domain should be converted into frequency-domain to obtain more information about the individual sources of vibration [16]. The most applicable method to convert the vibration signal is Fourier Transform. However, Fourier Transform becomes time-consuming to applied in a set of time-series data. It requires sequences of calculation steps including solving a discrete signal. Thus, Currently, a Fast Fourier Transform (FFT) algorithm is widely used because the conversion becomes fast. 
Spectrum of vibration displayed the fault symptomps through the dominant frequencies and the harmonics. Every faults has its specific spectrum characteristic which differentiates it from the others. There are several faults can be detected such as unbalance, misalignment, mechanical looseness, bearing defects, resonance, bent shaft, and gear deflect. Unbalance, for inscance, presented by a predominant 1x RPM frequency of vibration. To get more specific classification needs a further analysis. However, only spectrum diagnosis is considered in this paper. In this study, the dominant frequencies also is compared to the natural frequency of the system in order to investigate the possibility of resonance occurs. The resonance should be avoided since it causes the components to vibrate excessively and damage the system.

Table 1. Severity criterion [14][15].

\begin{tabular}{|c|c|c|}
\hline Rating & Severity & Description \\
\hline 1 & None & There is no effect \\
\hline 2 & Very small & The effects can be ignored to the performance \\
\hline 3 & Small & The system performance affected slightly \\
\hline 4 & Very low & Very slight effect on the system performance \\
\hline 5 & Low & Decrease the performance gradually \\
\hline 6 & Medium & System operates with decreasing performance \\
\hline 7 & High & System operates but is not fully operational \\
\hline 8 & Very high & The system does not operate \\
\hline 9 & Dangerous with warning & System failure produces damaging effects \\
\hline 10 & $\begin{array}{c}\text { Dangerous without } \\
\text { warning }\end{array}$ & $\begin{array}{c}\text { System failure produces a very dangerous } \\
\text { effect }\end{array}$ \\
\hline
\end{tabular}

Table 2. Occurance criterion [14][15].

\begin{tabular}{|c|c|c|}
\hline Rating & Occurance & Description \\
\hline 1 & None & Mostly no damage \\
\hline $2-3$ & Low & Very slight failure \\
\hline $4-6$ & Medium & Infrequent failure \\
\hline $7-8$ & High & Repeated failure \\
\hline $9-10$ & Very high & Frequent failure \\
\hline
\end{tabular}

Table 3. Detection criterion [14][15].

\begin{tabular}{|c|c|c|}
\hline Rating & Detection & Description \\
\hline 1 & Certain & Potential cause and failure will always be detected \\
\hline 2 & Very high & Very high possibility to be detected \\
\hline 3 & High & High possibility to be detected \\
\hline 4 & Middle to up & Moderately high possibility to be detected \\
\hline 5 & Medium & Moderate possibility to be detected \\
\hline 6 & Low & Low possibility to be detected \\
\hline 7 & Very low & Very low possibility to be detected \\
\hline 8 & Small & Small possibility to be detected \\
\hline 9 & Very small & Very small possibility to be detected \\
\hline 10 & Not Sure & Undetectable \\
\hline
\end{tabular}




\section{ANALYSIS}

All statements of the FMEA questionnaire have a correlation coefficient larger than the critical value and reliability value larger than $80 \%$. It means that the questionnaire deserves to measure the possible damages of the steam turbine components. The result of the FMEA criterion assessment including the RPN was summarized in Table 4.

Table 4. RPN of the steam turbine components.

\begin{tabular}{|l|c|c|c|c|}
\hline \multicolumn{1}{|c|}{ Components } & Severity & Occurance & Detection & RPN \\
\hline Coupling & 6.4 & 4 & 4.8 & 122.88 \\
\hline Labyrinth seal & 5.8 & 4 & 4.2 & 97.44 \\
\hline Bearing & 5.3 & 4.2 & 4.3 & 95.71 \\
\hline Diaphragm & 5.6 & 4 & 4.26 & 95.42 \\
\hline Turbine control valve & 6.6 & 3.6 & 4 & 95.04 \\
\hline Turbine stop valve & 6.4 & 3.6 & 4 & 92.16 \\
\hline Shaft & 5.1 & 3.65 & 4.3 & 80.04 \\
\hline Blade & 5.06 & 4 & 3.93 & 79.54 \\
\hline Casing & 4.66 & 3.8 & 4.13 & 73.13 \\
\hline
\end{tabular}

The component with the highest RPN is Coupling, 122.8, and the lowest is Casing, 73.13. A Pareto chart was created based on RPN as shown in Figure 3.

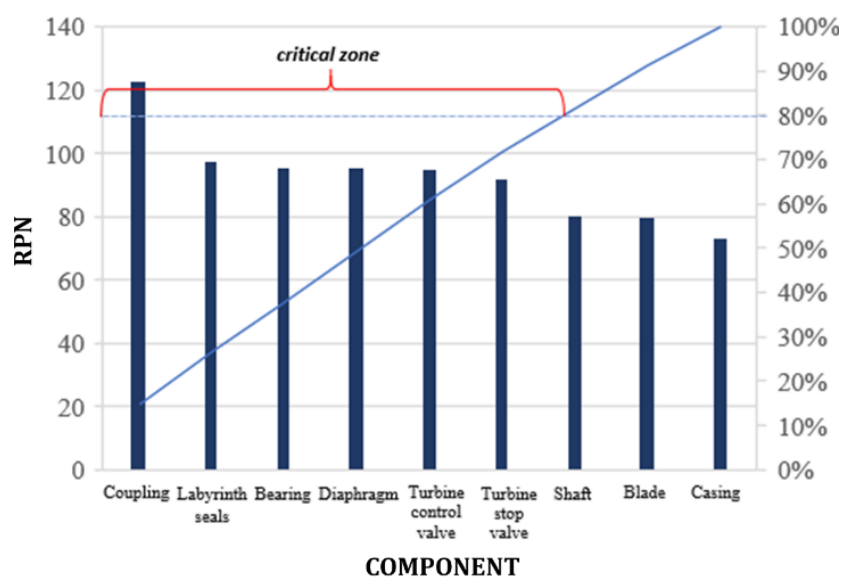

Figure 3. Pareto chart of the steam turbine.

The critical components are coupling, labyrinth seals, bearing, diaphragm, turbine control valve, and turbine stop valve. Therefore, reliability calculation conducted to evaluate the maintenance interval of each critical component.

- Coupling

Time to failure of coupling followed normal distribution with the value of index of fit is 0.97409 and $\mathrm{H}_{0}$ of Kolmogorov-Smirnov is accepted. The distribution has mean $(\mu)$ 16,693.3 and standard deviation $(\sigma)$ 8,663.618. From the estimated parameter, the MTTF of the coupling reached at $16,693.3$ 
hours. The expected reliability of $80 \%$ and $90 \%$ reached after 9,402 hours and 5,592 hours of operation.

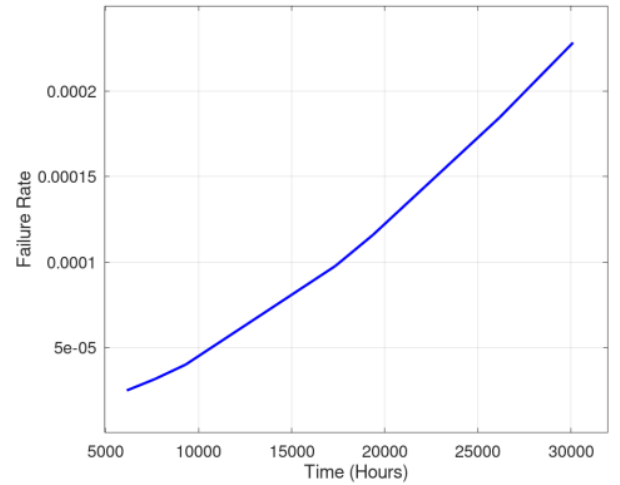

(a)

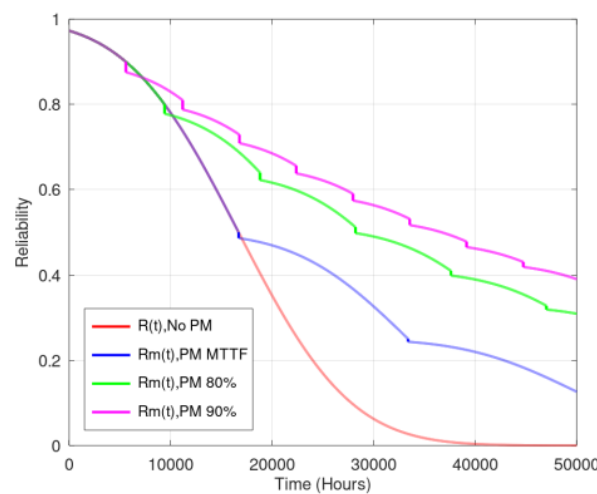

(b)

Figure 4. Failure rate (a) and reliability evaluation (b) of the coupling.

Failure rate of the coupling increases over the time. Based on the FMEA, potential failure of the coupling is misalignment. Misalignment occurs due to imperfect alignment of turbine shaft. In a poor condition, it allows the component to vibrate and damage the system. In order to prevent the damage, maintenance scheduled should be performed considering the estimated proper interval. From Figure 4.b, the maintenance interval of expected reliability at $90 \%$ can maintain and increase the reliability higher than the other intervals.

- $\quad$ Labyrinth seals

Labyrinth seals's TTF followed Weibull distribution with the value of index of fit is 0.96347 and $\mathrm{H}_{0}$ of Mann's test is accepted. The estimated value of the shape parameter $(\beta)$ is 1.6026 and the scale parameter $(\theta)$ is $11,705.5$. MTTF of the labyrinth seals is $10,493.3$ hours. The expected reliability of $80 \%$ and $90 \%$ reached after 4,591 hours and 2,875 hours of operation.

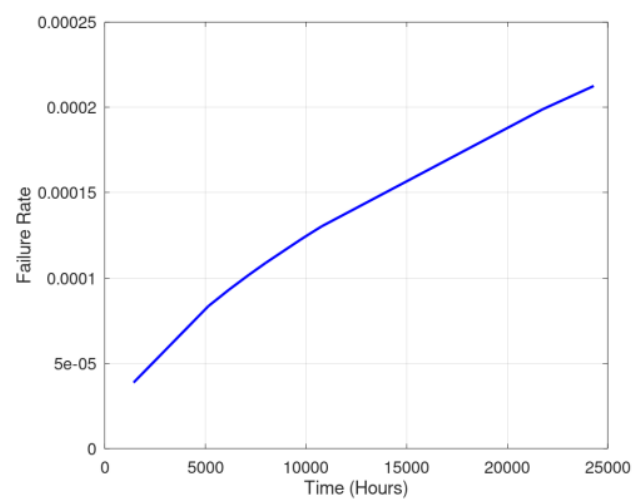

(a)

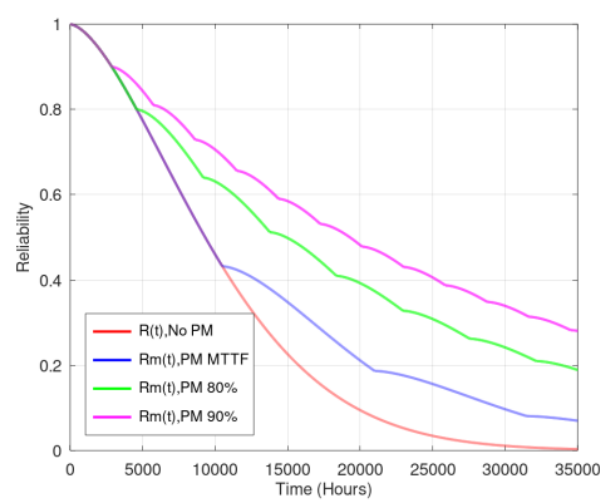

(b)

Figure 5. Failure rate (a) and reliability evaluation (b) of the labyrinth seals.

Failure rate of the labyrinth seals increases over the time. Based on the FMEA, there are several potensial failures of the labyrinth seals such as 
erosion, corrosion, and rubbing. The erosion and corrosion occur due to the low quality of steam purity that indicated by the presence of droplets and corrosive substances. The precense of droplets will scrape the labyrinth seals material as well as corrosive substances. Gradually, it causes steam leakage and decreasing performance because of the degradation of materials. On the other hand, rubbing of the labyrinth seals occurs when the shaft hits the labyrinth seals surface. The physical contact conceivable to have happened because the gap between labyrinth seals and shaft narrows due to the expansion of the material. After evaluating the reliability, the maintenance interval of expected reliability at $90 \%$ can maintain and increase the reliability higher than the other intervals.

- Bearing

Bearing's TTF followed Weibull distribution with the value of index of fit is 0.98882 and $\mathrm{H}_{0}$ of Mann's test is accepted. The estimated value of shape parameter $(\beta)$ is 1.0855 and scale parameter is $(\theta) 12,619.49$. MTTF of the bearing is 12,231 hours. The expected reliability of $80 \%$ and $90 \%$ are reached after 3,170 hours and 1,588 hours of operation.

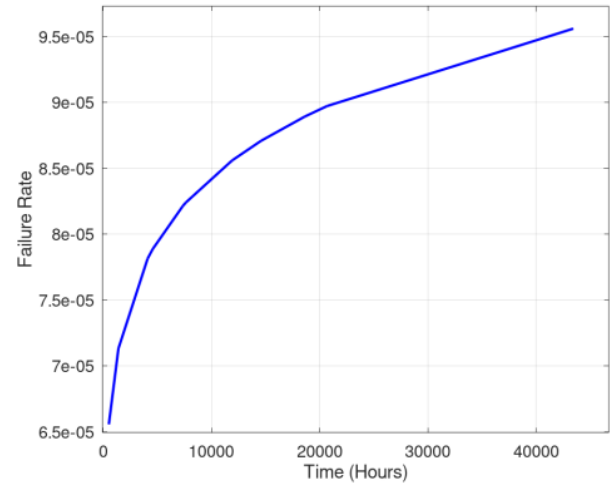

(a)

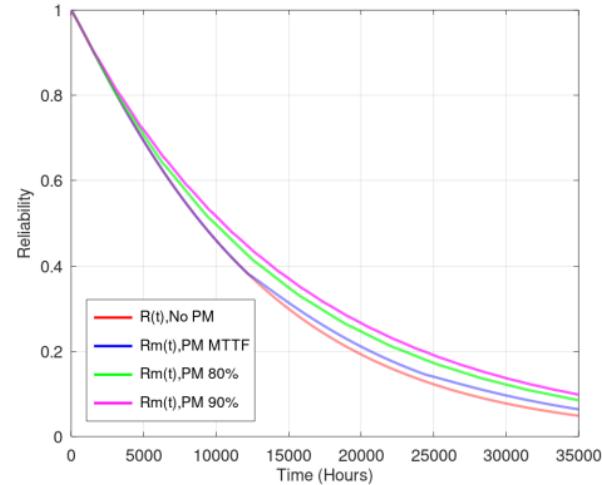

(b)

Figure 6. Failure rate (a) and reliability evaluation (b) of the bearing.

Failure rate of the bearing increases over the time. Based on the FMEA, the potential failures of the bearings are wear and cracking. The failures occur because of frictional forces appeared when bearing carried out the rotating shaft and turbine rotors. That condition generates deformation on bearing's material and produce loose-fitting to the shaft. Therefore, vibration will be occurred and it damage the system and the bearings itself. From Figure 6.b, the maintenance interval of expected reliability at $90 \%$ can maintain and increase the reliability higher than other intervals. However, the reliability increase slighty for all maintenance intervals. The reliability under preventive maintenance depends on the shape parameter of the distribution. If the shape parameter of component is exactly 1 , preventive maintenance does not effect the reliability [13]. It make a sense that the increase of the bearings's reliability is less significant due to the shape parameter obviously close to 1 . By comparing each maintenance intervals, 
the maintenance interval of expected reliability at $90 \%$ is better than the others.

- Diaphragm

Diaphragm's TTF followed normal distribution with the value of index of fit is 0.9966 and $\mathrm{H}_{0}$ of Kolmogorov-Smirnov test is accepted. The distribution has mean $(\mu) \quad 14,849$ and standard deviation $(\sigma)$ 8,318.75. MTTF of the diaphragm is 14,849 hours. The expected reliability of $80 \%$ and $90 \%$ are reached after 7,848 hours and 4,189 hours of operation.

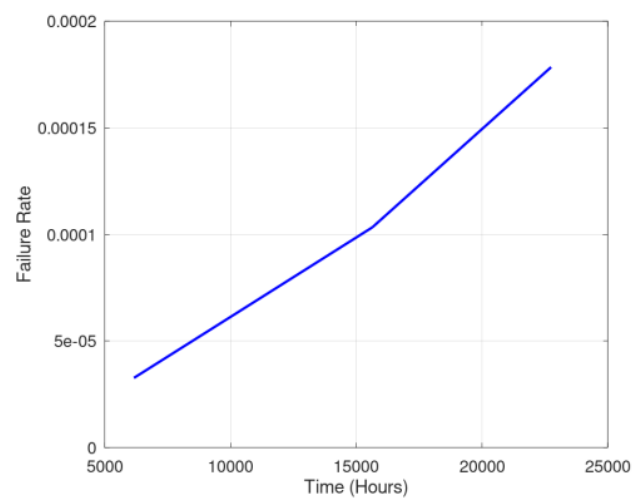

(a)

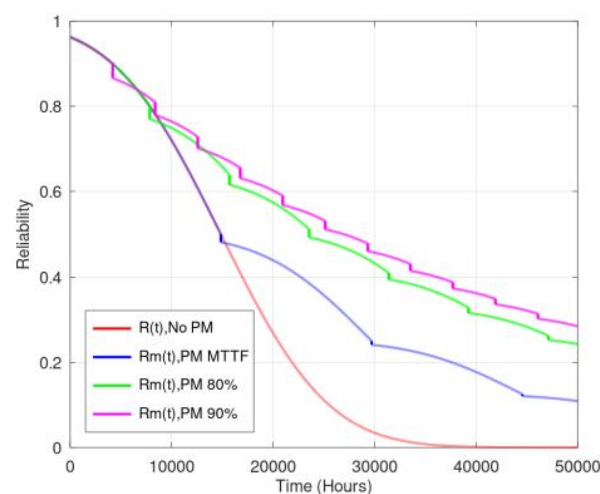

(b)

Figure 7. Failure rate (a) and reliability evaluation (b) of the diaphragm.

Failure rate of the diaphragm increases over the time. Based on the FMEA, the potential failures of the diaphragm are erosion, corrosion, and scaling. The droplets and corrosive substance appear along with the steam, then deposited to the diaphragm surface. The sedimentation might contain silica which harden and form a crust. During the operation, the diaphragm material continuously has direct contact with steam flow. In that situation, the diaphragm meets the erosion, corrosion, and scaling. In the poor condition, the failures cause the vibration, cracking, increasing wear, and damage to the nozzle. Furthermore, the scale can decrease the steam velocity and clog the flow. It might create serious impact to the efficiency. From Figure $7 . b$, the maintenance interval of expected reliability at $90 \%$ can maintain and increase the reliability higher than other intervals.

- Turbine control valve

Turbine control valve's TTF followed Weibull distribution with the value of index of fit is 0.97875 and $\mathrm{H}_{0}$ of Mann's test is accepted. The estimated value of shape parameter $(\beta)$ is 1.222 and scale parameter is $(\theta) 7,082.2$. MTTF of the turbine control valve is 6,631.61 hours. The expected reliability of $80 \%$ and $90 \%$ are reached after 2,076 hours and 1,124 hours of operation. 


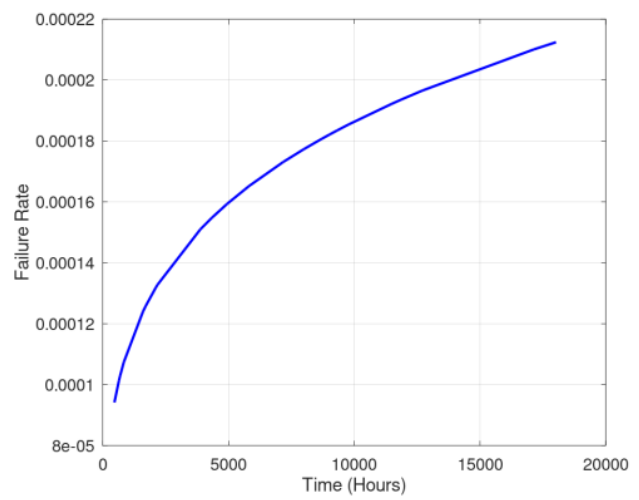

(a)

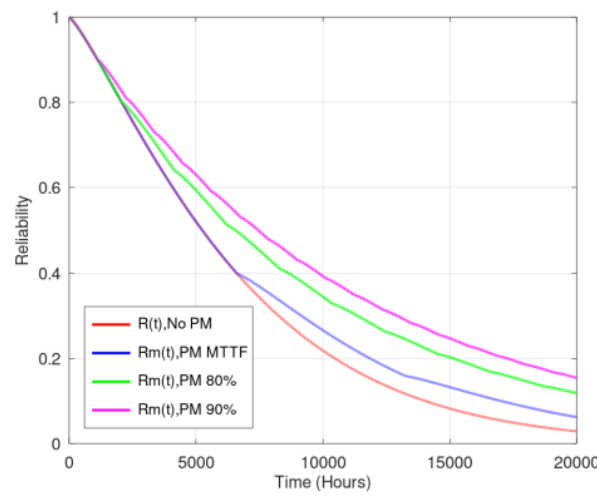

(b)

Figure 8. Failure rate (a) and reliability evaluation (b) of the turbine control valve.

The turbine control valve is used to regulate the amount of the steam enters to the turbine which can be set to the desired degree of openings. The opening or closing is done automatically by hydraulic actuator. The degree of openings refers to the demand of the output power. In the power plant, sometimes the demand is fluctuative. It causes the stem connected to the valve disc scrape the hydraulic fluid intensely. Based on the FMEA, the potential failure of turbine control valve is wear due to the fiction force on the stem. The failure effects to an imperfect opening or closing of the valve. That condition will affect the performance and the output power of the steam turbine. From Figure 8.a, the failure rate of this component increases over the time. The maintenance interval of expected reliability at $90 \%$ can maintain and increase the reliability higher than other intervals as shown in Figure 8.b.

- Turbine stop valve

Turbine stop valve's TTF followed Weibull distribution with the value of index of fit is 0.96305 and $\mathrm{H}_{0}$ of Mann's test is accepted. The estimated value of shape parameter $(\beta)$ is 1.2405 and scale parameter is $(\theta) 10,299$. MTTF of the turbine stop valve is $9,609.2$ hours. The expected reliability of $80 \%$ and $90 \%$ are reached after 3,074 hours and 1,679 hours of operation.

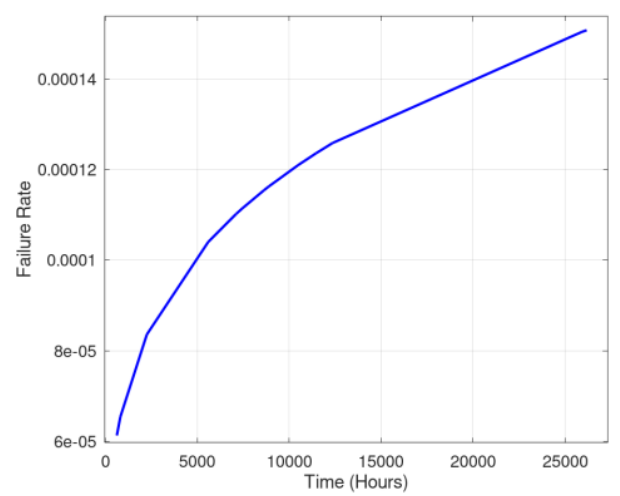

(a)

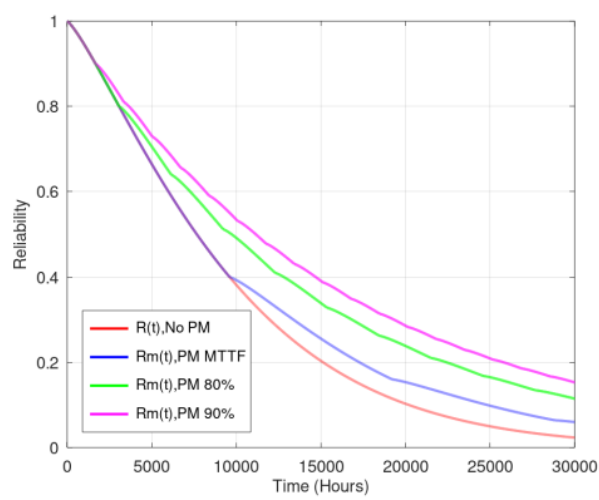

(b)

Figure 9. Failure rate (a) and reliability evaluation (b) of the turbine stop valve. 
The turbine stop valve is used to open or block the steam enters to the turbine by fully-opened or fully-closed hydraulic actuator. Based on the FMEA, the potential failure of the turbine stop is corrosion. The corrosion is occurred to the actuator because of corrosion substance contained in hydraulic fluid. In the poor condition, the stop valve can not block the entire steam even when the actuator set to fully-closed position. From Figure 9.a, the failure rate of this component increases over the time. The maintenance interval of expected reliability at $90 \%$ can maintain and increase the reliability higher than other intervals as shown in Figure 9.b.

The reliability evaluation showed that reliability under preventive maintenance increase from the reliability without maintenance. From the evaluation result, all components achieved the highest increasing reliability by implementing the maintenance interval based on the expected reliability of $90 \%$. Nevertheless, the condition monitoring is still needed in order to predict the failures that might be appeared on the steam turbine at the current conditions. The steam turbine-generator system has 10 bearings. However, the vibration analysis only conducted to bearing 5 and 6 which very high vibrations was appeared in the past.

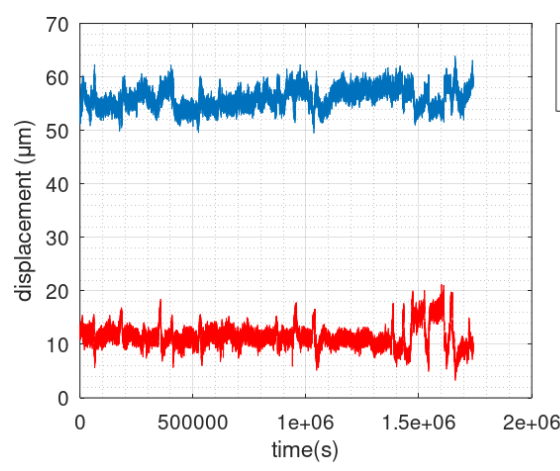

(a)

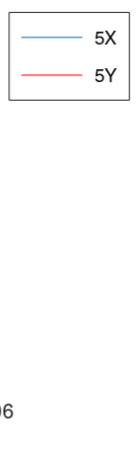

Figure 10. Time domain displacement of (a) bearing 5 and (b) bearing 6 .

Figure 10 displayed the displacement amplitude over the time. From the graph, vibration at X direction was higher than $\mathrm{Y}$ direction both on bearing 5 and bearing 6 . Therefore, only the vibration of $\mathrm{X}$ direction is discussed in this paper.

After converting the time domain data into frequency domain as shown in Figure 11, the dominant frequencies were analyzed. From the result of Figure 11.a, the dominant frequencies appeared at $0.23 \mathrm{~Hz}, 0.51 \mathrm{~Hz}$, and 1.06 $\mathrm{Hz}$. However, the dominant frequencies are still safe compared to the natural frequency which is appeared at $13.91 \mathrm{~Hz}$. From Figure 11.b, the dominant frequency does not exist on the spectrum. Based on the spectrum shown, both bearing 5 and bearing 6 did not indicate any failure since the dominant frequencies even smaller than 1x RPM. Therefore, the condition of the steam turbine remains in a good condition. However, the condition monitoring should be conducted continuously. 


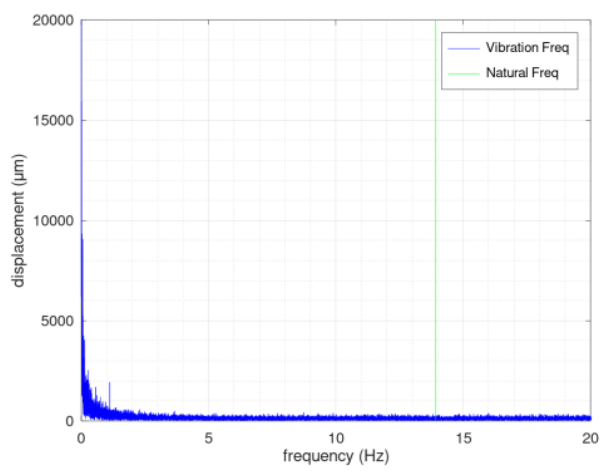

(a)

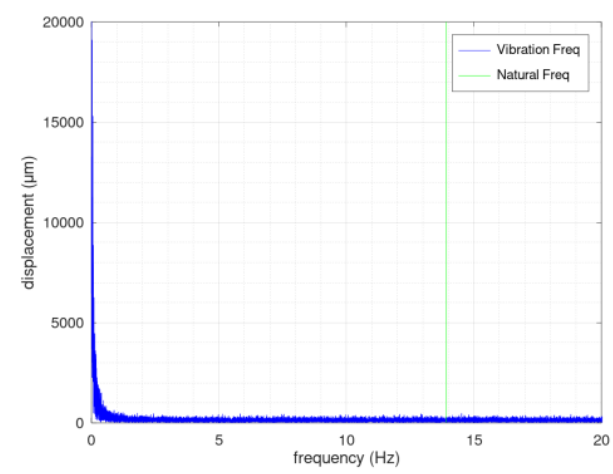

(b)

Figure 11. FFT spectrum of (a) bearing 5 and (b) bearing 6 .

\section{CONCLUSION}

An application to conduct reliability and vibration analysis is proposed in this paper. An interactive user interface is developed in order to make the analysis becomes accurate. The steam turbine has six critical components which are the coupling, labyrinth seals, bearing, diaphragm, turbine control valve, and turbine stop valve. Depending on the value of RPN, the coupling has the most severe condition with a value of 122.88. By varying the maintenance intervals, the result shows that maintenance interval refers to the expected reliability of $90 \%$ produce the highest reliability improvement. Based on the vibration analysis, there are no failure symptoms detected as well as the vibration synchronization result. The dominant frequency of vibration values around $1 \mathrm{~Hz}$ and below, while the natural frequency is 13.91 Hz. It shows that the vibration frequency is remote from the natural frequency. Therefore, the steam turbine remains in a good condition. However, vibration monitoring should be performed periodically to obtain the updated information on the steam turbine conditions.

\section{References}

[1] Cornelius Scheffer, Paresh Girdhar, Practical Machinery Vibration Analysis and Predictive Maintenance, Newnes, Ed. 1, 2004.

[2] Beny Cahyono, Dwi Priyanta, Fakhri Rizqullah Fajar Ramadhan, Vibration Spectrum Analysis for Indicating Damage on Turbine and Steam Generator Amurang Unit 1, International Journal of Marine Engineering Innovation and Research, Vol. 2, No.1, pp. 51-58, 2017.

[3] Almar Gunnarsson, Ari Elisson, Magnus Jonsson, Runar Unnthorsson, Specified Maintenance of Steam Turbines in Geothermal Power Plants, Proceedings of the ASME 2013 Power Conference, America, Vol. 1, POWER2013-98088, 2013.

[4] Satyendra Dhurvey, Pradeep Kumar Soni, Preventive Maintenance of Steam Turbine used in Thermal Power Plant by Reliability 
Investigation and FMEA, International Journal of Science and Research (IJSR), Vol. 7, No. 6, pp. 18-22, 2018.

[5] Ali Musyafa, Ronny D, Noriyati, Silvana R. Dacosta, S. Komaryadi, Reliability and Maintainability Assessment of the Steam Turbine Instrumentation System for optimization Operational Availability System at Fertilizer Plant, Australian Journal of Basic and Applied Sciences, Vol. 8, No.13, pp. 132-139, 2014.

[6] Apol Pribadi Subriadi, Nina Fadilah Najwa, The Consistency Analysis of Failure Mode and Effect Analysis (FMEA) in Information Technology Risk Assessment. Heliyon, Vol. 6, No. 1, p.e03161, 2020.

[7] D.N. Dewangan, Manoj Kumar Jha, Y.P. Banjare, Reliability Investigation of Steam Turbine Used in Thermal Power Plant, International Journal of Innovative Research in Science, Engineering and Technology, Vol. 3, No. 7, pp.14915-14923, 2014.

[8] Rahul D. Mankar, M.M, Gupta, Vibration Based Condition Monitoring by using Fast Fourier Transform "A Case On A Turbine Shaft", Proceedings of International Conference on Industrial Automation and Computing (ICIAC), Vol. Spesial : ICIAC(AS), pp. 11-15, 2014.

[9] Ge Li-juan, Zhang Chun-hui, Hao Min, Zhang Yong, Vibration Analysis of The Steam Turbine Shafting Caused by Steam Flow, Telkomnika, Vol. 11, No.8, pp.4422-4432, 2013.

[10] Rainer Nordmann, Lateral Turbine and Generator Vibrations Analysis and Mitigation, Energiforsk, Report number : 294, 2016.

[11] Tshimangadzo Mudau, Robert Murray Field, Rotordynamic Analysis of the AM600 Turbine-Generator Shaftline, Energies, Vol. 11, No. 12, p. 3411, 2018.

[12] J.P. Verma, Data Analysis in Management with SPSS Software. Springer Science \& Business Media. 2012.

[13] Charles E. Ebeling, An Introduction to Reliability and Maintainability Engineering, McGraw-Hill, 1997.

[14] Mohammed Ben-Daya, Salih O. Duffuaa, Abdul Raouf, Jezdimir Knezevic, Daoud Ait-Kadi, Handbook of Maintenance Management and Engineering, Springer, 2009.

[15] Muhammad Nurtanto, Ita Novita Sari, Sulaeman Deni Ramdani, Moh Fawai, Failure Mode and Effect Analysis (FMEA) as Treatment of Predictive Prevention and Leakage of Boiler Type Balance Draf Fan. VANOS Journal of Mechanical Engineering Education, Vol. 3, No. 2, pp. 173-184, 2018.

[16] H. A. Searle, Steam Turbine Condition Monitoring by Vibration Analysis, Proceedings of The South African Sugar Technologists' Association, pp. 101-106, 2007. 